Archived version from NCDOCKS Institutional Repository http://libres.uncg.edu/ir/asu/

\title{
Appalachy̆an
}

B O O N E, NORTH CAROLINA

\section{A 45-Minute Vigorous Exercise Bout Increases Metabolic Rate For 14 Hours}

\author{
By: \\ Amy M. Knab, R. Andrew Shanely, Karen D. Corbin, \\ Fuxia Jin, Wei Sha, and David C. Nieman
}

\begin{abstract}
Introduction: The magnitude and duration of the elevation in resting energy expenditure after vigorous exercise have not been measured in a metabolic chamber. This study investigated the effects of inserting a 45 -min vigorous cycling bout into the daily schedule versus a controlled resting day on 24 -h energy expenditure in a metabolic chamber. Methods: Ten male subjects (age $=22-33 \mathrm{yr}$ ) completed two separate 24-h chamber visits (one rest and one exercise day), and energy balance was maintained for each visit condition. On the exercise day, subjects completed 45 min of cycling at 57\% Wmax (mean T SD $=$ $72.8 \% \mathrm{~T} 5.8 \% \mathrm{~V}^{\cdot} \mathrm{O} 2 \mathrm{max}$ ) starting at 11:00 a.m. Activities of daily living were tightly controlled to ensure uniformity on both rest and exercise days. The area under the energy expenditure curve for exercise and rest days was calculated using the trapezoid rule in the EXPAND procedure in the SAS and then contrasted. Results: The 45-min exercise bout resulted in a net energy expenditure of $519 \mathrm{~T} 60.9 \mathrm{kcal}(\mathrm{P}$ $\mathrm{G} 0.001$ ). For $14 \mathrm{~h}$ after exercise, energy expenditure was increased $190 \mathrm{~T} 71.4 \mathrm{kcal}$ compared with the rest day (P G 0.001). Conclusions: In young male subjects, vigorous exercise for 45 min resulted in a significant elevation in postexercise energy expenditure that persisted for $14 \mathrm{~h}$. The $190 \mathrm{kcal}$ expended after exercise above resting levels represented an additional $37 \%$ to the net energy expended during the 45-min cycling bout. The magnitude and duration of increased energy expenditure after a 45 -min bout of vigorous exercise may have implications for weight loss and management.
\end{abstract}

Amy M. Knab, R. Andrew Shanely, Karen D. Corbin, Fuxia Jin, Wei Sha, and David C. Nieman (2011). "A 45Minute Vigorous Exercise Bout Increases Metabolic Rate for 14 Hours" American College of Sports Medicine. Version of Record Available @ (DOI: 10.1249/MSS.0b013e3182118891) 


\title{
A 45-Minute Vigorous Exercise Bout Increases Metabolic Rate for 14 Hours
}

\author{
AMY M. KNAB ${ }^{1}$, R. ANDREW SHANELY ${ }^{1}$, KAREN D. CORBIN ${ }^{2}$, FUXIA JIN ${ }^{1}$, WEI SHA ${ }^{3}$, and DAVID C. NIEMAN ${ }^{1}$ \\ ${ }^{1}$ Human Performance Laboratory, Appalachian State University, North Carolina Research Campus, Kannapolis, NC; \\ ${ }^{2}$ University of North Carolina at Chapel Hill, Nutrition Research Institute, North Carolina Research Campus, Kannapolis, \\ NC; and ${ }^{3}$ Bioinformatics Research Center, University of North Carolina at Charlotte, North Carolina Research Campus, \\ Kannapolis, $N C$
}

\begin{abstract}
Introduction: The magnitude and duration of the elevation in resting energy expenditure after vigorous exercise have not been measured in a metabolic chamber. This study investigated the effects of inserting a 45-min vigorous cycling bout into the daily schedule versus a controlled resting day on 24-h energy expenditure in a metabolic chamber. Methods: Ten male subjects (age $=22-33$ yr) completed two separate 24-h chamber visits (one rest

and one exercise day), and energy balance was maintained for each visit condition. On the exercise day, subjects completed 45 min of cycling at $57 \% W_{\max }$ (mean T SD $=72.8 \% \mathrm{~T} 5.8 \% \mathrm{~V} \mathrm{O}_{2 \max }$ ) starting at 11:00 a.m. Activities of daily living were tightly controlled to ensure uniformity on both rest and exercise days. The area under the energy expenditure curve for exercise and rest days was calculated using the trapezoid rule in the EXPAND procedure in the SAS and then contrasted. Results: The 45-min exercise bout resulted in a net energy expenditure of $519 \mathrm{~T} 60.9 \mathrm{kcal}$ ( $P$ G 0.001). For $14 \mathrm{~h}$ after exercise, energy expenditure was increased $190 \mathrm{~T} 71.4 \mathrm{kcal}$ compared with the rest day ( $P$ G 0.001). Conclusions: In young male subjects, vigorous exercise for 45 min resulted in a significant elevation in postexercise energy expenditure that persisted for $14 \mathrm{~h}$. The $190 \mathrm{kcal}$ expended after exercise above resting levels represented an additional $37 \%$ to the net energy expended during the 45-min cycling bout. The magnitude and duration of increased energy expenditure after a 45-min bout of vigorous exercise may have implications for weight loss and management. Key Words: EXERCISE, ENERGY EXPENDITURE, WHOLE BODY CALORIMETRY, METABOLIC CHAMBER, RESTING METABOLIC RATE
\end{abstract}

M easurement of the various components of energy expenditure including the resting metabolic rate (RMR) has improved our understanding of energy balance as it relates to human obesity. Accurate assessment of RMR requires sophisticated methodologies including direct and indirect calorimetry. Open-circuit indirect calorimetry Douglas bag systems and metabolic carts are most commonly used when measuring RMR, but measurement time is typically limited to $15-30 \mathrm{~min}$ and then extrapolated to 24-h periods. Whole-room indirect calorimeters (i.e., metabolic chambers) allow extended measurement of energy expenditure with tight control of energy intake and the daily schedule.

Studies using Douglas bag systems and metabolic carts have shown that 15 - 30 min of moderate to vigorous exer- cise causes a small increase in RMR that persists for a short time after exercise (25). One study of 10 male triathletes, for example, showed that three separate cycling bouts of 20-, $30-$, and 60-min duration and 75\%, 50\%, and 50\% maximum aerobic capacity, respectively, resulted in $12-30$ net calories expended more than 20 - 33 min after exercise (25). Others report an extended increase in postexercise energy expenditure after just 20 min of cycling at $70 \%$ maximum aerobic capacity (3), and differences between studies may be related to control of subject energy intake and daily activities. Several investigators emphasize that elevations in postexercise energy expenditure depend on the degree of homeostatic disturbance and that RMR is elevated especially after high-intensity long-duration exercise $(6,23)$. For example, rates for postexercise energy expenditure were elevated for $0.3,3.3$, and $10.5 \mathrm{~h}$ in six males cycling for $80 \mathrm{~min}$ at $29 \%, 50 \%$, and $75 \%$ of maximum aerobic capacity (4). Methods using indirect calorimetry have suggested that the magnitude of the elevation in energy expenditure after exercise is dependent on the intensity of the exercise (15); thus, resolving the issue of the duration and magnitude of the increase in energy expenditure after exercise bouts is important when considering the potential effect on total 24-h energy expenditure.

Metabolic chambers have been used to investigate the effects of physical activity on substrate utilization $(18,19,26)$ 
and 24-h energy expenditure $(21,24)$. However, few studies to date have analyzed the effects of physical activity on postexercise net energy expenditure during a 24-h period. Dionne et al. (9) investigated the effect of moderate-intensity exercise $\left(50 \% \vee \mathrm{O}_{2 \max }\right.$ for $60 \mathrm{~min}$ ) on 24-h energy expenditure and substrate utilization in eight young healthy males and reported no difference in 24-h energy expenditure or respiratory quotient $(\mathrm{RQ})$ between control and exercise sessions. Subjects exercised in the middle of the afternoon outside of the chamber and immediately ingested a milk shake that equaled the energy expended during exercise. These research design characteristics and the moderate intensity of the exercise bout may explain the reported results. Treuth et al. (29) reported an increase in 24-h energy expenditure when contrasting high- and low-intensity exercise bouts, but the research design did not include a rest day for the determination of the magnitude and duration of postexercise net energy expenditure.

This study investigated the effect of $45 \mathrm{~min}$ of vigorous cycling (57\% $W_{\max }$ or $\mathrm{E} 70 \%$ V $\left.\mathrm{O}_{2 \max }\right)$ on postexercise RMR as measured in a metabolic chamber, under tightly controlled conditions of daily living. The exercise session was conducted late in the morning and contrasted with a rest day to determine both the magnitude and duration of vigorous exercise on postexercise energy expenditure.

\section{METHODS}

Subjects. Ten healthy male subjects (age range $=22-$ 33 yr) were recruited via mass advertisement. Inclusion criteria included the following: subjects had to be nonsmokers, in good physical condition and capable of cycling vigorously for $45 \mathrm{~min}$, and with no adverse medical issues including anxiety within closed spaces. Written informed consent was obtained from each subject, and the experimental procedures were approved by the institutional review board of Appalachian State University.

Baseline testing. Two weeks before the study, subjects came to the North Carolina Research Campus Human Performance Laboratory for baseline testing that included body composition and $\mathrm{V} \mathrm{O}_{2 \max }$ testing and a full orientation regarding study requirements. Body composition was measured via dual-energy X-ray absorptiometry (GE Lunar iDXA; Milwaukee, WI). RMR was calculated using a fatfree mass - based equation (418 + (20.3 fat-free mass)) (2). This estimated RMR was used for calculating total dietary energy intake while in the metabolic chamber (1.4RMR) and then adjusted using measured data (see below). $V \mathrm{O}_{2 \max }$ was measured using the COSMED Quark CPET metabolic cart (Rome, Italy) with the Lode cycle ergometer (Lode Excalibur Sport; Lode B.V., Groningen, The Netherlands) and a graded protocol with a $15-\mathrm{WImin}^{\mathrm{j} 1}$ increase to exhaustion (28). Several criteria were used to determine $\mathrm{V}$ $\mathrm{O}_{2 \max }$ including an RER of 1.15 and higher, a plateau of oxygen consumption, and a maximal HR within 12 beats of the predicted maximum.
Study design. Ten subjects completed two sessions in the chamber on nonconsecutive days (Monday and Wednesday or Tuesday and Thursday of the same week). During the first session, subjects remained in a rested state and engaged in no exercise while following the schedule of events depicted on the $x$ axis in Figure 1. During the second session, the same schedule was followed except that subjects completed $45 \mathrm{~min}$ of exercise on a cycle ergometer at $57 \%$ $W_{\max }$. This order was followed to avoid the potential influence of the exercise session on energy expenditure during the subsequent session in the metabolic chamber. The duration of $45 \mathrm{~min}$ corresponds to the middle of the range suggested by the physical activity guidelines for Americans (30 - 60 min). Fifty-seven percent $W_{\max }$ corresponds to a vigorous intensity of approximately $70 \% \mathrm{~V} \mathrm{O}_{2 \max }$. Subjects were instructed to avoid exercise on the days before entering the chamber and to consume foods from a specific food list that has been used in prior studies to achieve a $\mathrm{CHO}$ intake of approximately 55\% total energy (20). Subjects were also instructed to avoid any supplements, including caffeine, for the duration of the study.

At approximately 7:30 a.m., subjects reported to the metabolic chamber in an overnight fasted state (no food or beverage other than water from 11:00 p.m.). At 8:00 a.m., subjects were sealed in the chamber and were asked to stay in a seated position unless they needed to use the restroom or perform other necessary daily activities (e.g., washing hands, brushing teeth). Breakfast was served through an air lock passage at 9:00 a.m. On rest days, subjects remained in a seated position from breakfast to 12:30 p.m. when they were asked to get up and stretch for $2 \mathrm{~min}$. On both rest and exercise days starting at 12:30 p.m., subjects were asked to get up and stretch for 2 min every hour until 6:30 p.m.

Lunch was served at 1:30 p.m., and dinner was served at 7:00 p.m. Subjects were asked to remain in the seated

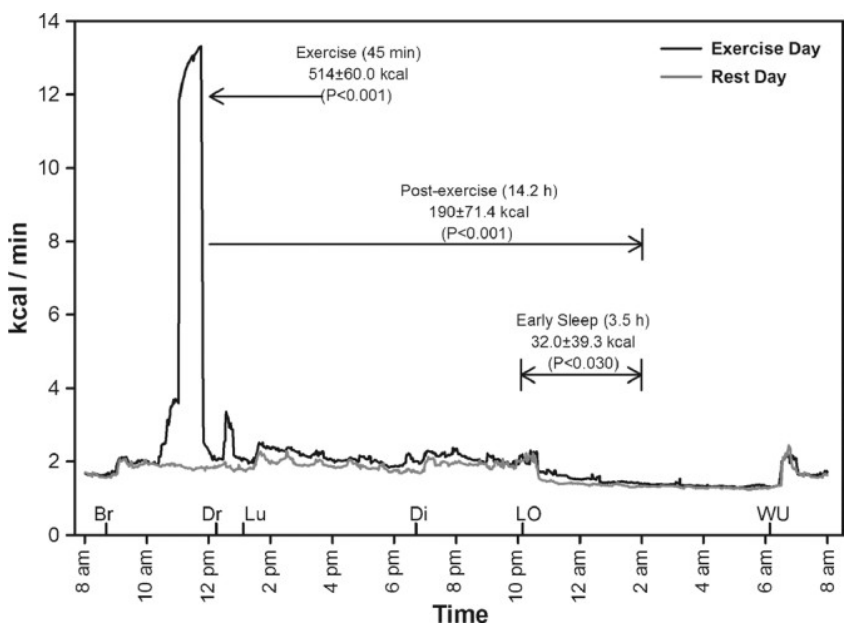

FIGURE 1-Average 24-h energy expenditure on rest and exercise days. Forty-five minutes of cycling resulted in 519 T $60.9 \mathrm{kcal}$ of energy expended above rest day ( $P$ G 0.001$)$, whereas $190 \mathrm{~T} 71.4 \mathrm{kcal}$ was expended above levels on the rest day for $14.2 \mathrm{~h}$ after exercise $(P \mathrm{G}$ 0.001). Net energy expenditure difference from the start of sleep to $18 \mathrm{~h}$ after exercise was $32.0 \mathrm{~T} 39.3 \mathrm{kcal}(P=0.030)$. 
position until 8:00 p.m., at which point they were able to relax and lie down but not go to sleep. Bed time was at 10:30 p.m., and subjects were asked to lie down even if they were not sleeping. Subjects were woken at 6:30 a.m. and were allowed to move about the chamber and gather their belongings. At 7:15 a.m., subjects exited the chamber.

On arrival on the exercise day, subjects were oriented to the cycle ergometer and were instructed how to adjust wattage and report HR from the HR monitor (Polar HR Monitor; Kempele, Finland) during the test. The cycle ergometer was adjusted to fit the leg length of the subject. At 10:40 a.m., subjects prepared for exercise (e.g., stretch, change clothes, arrange room with towels and music). Subjects mounted the cycle ergometer and started pedaling at 11:00 a.m. The cycling protocol consisted of 2 min at 50\% of the workload $\left(57 \% W_{\max }\right), 2$ min at $75 \%$ of the workload, $41 \mathrm{~min}$ at $100 \%$ of the workload, and another 2 min at $50 \%$ of the workload. Oxygen consumption and energy expenditure were measured continuously during the exercise bout, with HR recorded every $5 \mathrm{~min}$. Immediately after exercise, subjects sat down for 40 min until 12:30 p.m. At 12:30 p.m., subjects were allowed to clean themselves and change clothes and then stayed in the seated position until lunch at 1:30 p.m.

Description of metabolic chamber. Studies were conducted in the newly constructed metabolic chamber located at the University of North Carolina at Chapel Hill Nutrition Research Institute, Kannapolis, NC. The chamber was modeled after the chambers at the National Institute of Diabetes and Digestive and Kidney Diseases, Bethesda, MD (7). The University of North Carolina at Chapel Hill Nutrition Research Institute metabolic chamber is an opencircuit pull-type whole-room indirect calorimeter built with walk-in cooler panels. The metabolic chamber has a floor space of 10 feet 11 inches $\times 8$ feet 0.5 inches, a height of 7 feet 10 inches, and an air volume of 18,346 L when fully furnished. The room is equipped with a twin bed, bedside table, chair, toilet, mirror, sink, multimedia laptop, telephone, intercom, nurse call button, specimen refrigerator, iris ports for blood draws, and two air locks that serve as food and specimen passes. There is sufficient space to include a bike or treadmill inside the chamber. The metabolic chamber has three windows, two looking outside and one looking into the observation room.

An air conditioning system mixes the air in the chamber, maintaining a preset temperature and a relative humidity of G70\%. For this particular study, the average temperature maintained in the chamber was 23.1-C T 0.30-C, and the average chamber relative humidity was $54.6 \% \mathrm{~T} 1.5 \%$. Fresh conditioned air is passively drawn into the chamber from an adjacent buffer zone. Mixed expired air is drawn out of the metabolic chamber by a small fan placed at the outlet of the chamber through a centralized sampling apparatus designed with evenly spaced sectors to ensure equal sampling throughout the chamber. The flow is set manually and kept at a constant rate, typically $60 \mathrm{LImin}^{\mathrm{j} 1}$ (capacity is $\left.120 \operatorname{LImin}^{\mathrm{j} 1}\right)$. On the rest day, the flow rate was kept at $60 \mathrm{LImin}^{\mathrm{j} 1}$ for lean individuals and $100 \mathrm{LImin}^{\mathrm{j} 1}$ for individuals with weights $Q 130 \mathrm{~kg}$. On the exercise day, the flow rate was maintained at $120 \mathrm{LImin}^{\mathrm{j} 1}$ to account for ambient $\mathrm{CO}_{2}$ buildup during exercise. These flow rates were chosen on the basis of pilot data to assess the capacity of the chamber to handle increased $\mathrm{CO}_{2}$ loads.

Before measurements, a small sample of air was cooled to 1-C and dried, drawn by a diaphragm pump, and filtered. The $\mathrm{CO}_{2}$ and $\mathrm{O}_{2}$ analyzers are differential, and their fullscale readings were set for $0 \%-1 \%$. The metabolic chamber has a passive infrared motion sensor to measure spontaneous physical activity. Oxygen consumption, $\mathrm{CO}_{2}$ production, energy expenditure, $\mathrm{RQ}$, and percent activity were recorded each minute. The lag time is constant at the start and at the end of exercise. Advanced noise suppression and trend identification techniques allow for accurate measurement and time discrimination of the exercise plateau as seen by the gas analyzers. Results are then aligned with the start of the exercise time. The Weir equation for energy expenditure $(\mathrm{EE})\left(\mathrm{kcalImin}^{\mathrm{j} 1}\right)=3.941 \mathrm{~V} \mathrm{O}_{2}+1.106 \mathrm{~V} \mathrm{CO}_{2}$ was used for conversion of $\mathrm{V} \mathrm{O}_{2}\left(\operatorname{LImin}^{\mathrm{j} 1}\right)$ and $\mathrm{V} \mathrm{CO}_{2}\left(\mathrm{LImin}^{\mathrm{j} 1}\right)$ to kilocalories.

The analyzers were calibrated weekly using standard gas mixtures (zero gas is $\mathrm{E} 21 \% \mathrm{O}_{2}$, balanced nitrogen; span gas is $\mathrm{E} 20 \% \mathrm{CO}_{2}$, $\mathrm{E} 1 \% \mathrm{O}_{2}$, balanced nitrogen). The chamber was validated using a series of propane burn tests. Five propane burns were conducted at a flow rate of $60 \mathrm{LImin}^{\mathrm{j} 1}$. The $\mathrm{CO}_{2}$ recovery was $97.6 \% \mathrm{~T} 0.6 \%$ (mean $\mathrm{T} \mathrm{SD}$ ), and the $\mathrm{O}_{2}$ recovery was $99.1 \% \mathrm{~T} 0.4 \%$. Monthly propane tests were conducted to verify the accuracy of the chamber.

Before conducting trials in the chamber, we tested the reproducibility of the 24-h EE measurement. Ten subjects (including eight from the exercise portion of the study) completed two nonconsecutive sessions in the metabolic chamber (either Monday and Wednesday or Tuesday and Thursday of the same week). Subjects were fed the same three meals during both sessions in the chamber, and urine was collected for measurement of nitrogen. The average 24-h EE difference between the two chamber sessions was 66.5 T 74.2 kcalld $^{\mathrm{j} 1}$, corresponding to a $2.5 \%$ T $2.3 \%$ difference between days. For the eight subjects completing four separate days in the chamber, the average coefficient of variation for the three rest days was $2.3 \%$.

Design of metabolic diets. Diets during chamber days were designed to provide approximately $35 \%$ fat, $55 \%$ $\mathrm{CHO}$, and $15 \%$ protein. The same foods were served at all chamber visits, with the exception of the snacks provided on the exercise day to achieve energy balance. Calories were assigned to each subject on the basis of calculated RMR $\mathrm{x}$ 1.4. To calculate the amount of calories to provide, we took into account that $93 \%$ of energy content is metabolizable (27). Menus were designed and analyzed with the Esha Food Processor SQL software (Esha Research, Inc., Salem, OR). Meals were delivered at designated times and picked up 30 min later. Subjects were asked to consume all foods 
provided. Food intake was documented, and on the rare occasion that a subject did not eat all of the food provided,

the food was weighed back, and the nutrients were removed

from the final nutrient analysis. To ensure energy balance conditions, 3- and 7-h predictions of 24-h EE from the chamber software were used to modify the baseline menu. On the exercise day, snacks with the same nutrient composition as the base menu were provided to account for additional calories burned during exercise. Exercise EE was calculated, and approximately one-half of the calories needed to achieve energy balance were added to lunch. The final calories needed for energy balance were determined with the 7-h prediction. On the basis of this prediction, the balance of the needed calories was provided at dinner.

Statistical analysis. Two energy expenditure curves, one for the exercise day and one for the rest day, were generated for each subject with the $x$ axis representing time (min), and the $y$ axis representing energy expenditure (kcal). To determine the total energy expenditure for each activity

period (before exercise, exercise preparation, exercise, immediately after exercise, dress, from dress to sleep, sleep), the area under the energy expenditure curve for each activity period was calculated by using the trapezoid rule in the EXPAND procedure in SAS (version 9.1.3; SAS Institute,

Inc., Cary, NC). A paired $t$-test on the log-transformed area was performed to compare the energy expenditure of each activity period in the exercise day with the corresponding period in the rest day.

The total energy expenditure for each hour was also calculated using the area-under-the-curve method as described above. A paired $t$-test on the log-transformed area was performed to compare energy expenditure of each hour in the exercise day with the corresponding hour in the rest day.

The Shapiro - Wilk test in the UNIVARIATE procedure in SAS was used for normality check. The BenjaminiHochberg method for false discovery rate correction in the MULTTEST procedure in SAS was used for multiple testing corrections.

\section{RESULTS}

Characteristics of the 10 subjects completing the study are summarized in Table 1 . The young adult males in this study varied widely in body mass index, body composition, and aerobic fitness, and all successfully completed the total 47-min cycle ergometry exercise in the metabolic chamber.

Table 2 reports average workload, HR, oxygen consumption, and energy expenditure data for all subjects during the

\begin{tabular}{|c|c|c|c|}
\hline & MeanTSD & Minimum & Maximum \\
\hline Age (yr) & 25.4 Т 3.4 & 22 & 33 \\
\hline Height $(\mathrm{cm})$ & $180 \mathrm{~T} 8.02$ & 166 & 193 \\
\hline Weight $(\mathrm{kg})$ & 90.3 T 27.9 & 62.6 & 148 \\
\hline Body mass index $\left(\mathrm{kg} \mathrm{Im}^{\mathrm{j} 2}\right)$ & 27.9 T 6.9 & 20.1 & 39.8 \\
\hline Body fat (\%) & $21.9 \mathrm{~T} 11.4$ & 9.4 & 39.4 \\
\hline$\dot{\mathrm{V}}_{2 \max }\left(\mathrm{mLIkg}{ }^{\mathrm{j} 1} \operatorname{Imin}^{\mathrm{j} 1}\right)$ & $43.5 \mathrm{~T} 12.8$ & 22.9 & 62.5 \\
\hline $\mathrm{HR}_{\max }\left(\right.$ beatsImin $\left.{ }^{\mathrm{j} 1}\right)$ & $188 \mathrm{~T} 10.6$ & 166 & 200 \\
\hline
\end{tabular}

Workload $(W)_{j 1}$

HR (beatsImin )
HR (\% maximal)

$\mathrm{HR}(\%$ maximal)
$\dot{\mathrm{VO}}_{2}\left(\mathrm{LImin}^{\mathrm{j} 1}\right)$

$\dot{\mathrm{V}} \mathrm{O}_{2} \quad\left(\mathrm{mLIkg}^{\mathrm{j} 1} \mathrm{Imin}^{\mathrm{j} 1}\right)$

$\dot{\mathrm{VO}}_{2}$ (\% maximal)

Energy expenditure (kcalImin ${ }^{\mathrm{j} 1}$ )

exercise bout. The relative HR and oxygen consumption data indicate that this exercise bout set at $57 \% W_{\max }$ was at a vigorous level, as defined by the American College of Sports Medicine (1). Energy expenditure during the exercise bout was 6.1-fold greater than the corresponding energy expenditure on the rest day.

Table 3 summarizes the energy and macronutrient intakes and energy expenditure data during $24 \mathrm{~h}$ on rest and exercise days. A significantly higher energy intake occurred on the exercise compared with the rest day, with a mean

increase of $659 \mathrm{~T} 104 \mathrm{kcalId} \quad(P \mathrm{G} \mathrm{0.001).} \mathrm{The} \mathrm{percent} \mathrm{of}$ energy consumed as $\mathrm{CHO}$ and fat was slightly different on the exercise day; however, this difference corresponds to G0.6\%. Total energy expenditure was greater on the exercise versus the rest day by $750 \mathrm{~T} 121 \mathrm{kcalId}(P \mathrm{G} \mathrm{0.001)}$. On the rest day, energy intake was slightly below energy expenditure, with a mean difference of $38.0 \mathrm{~T} 89.3 \mathrm{kcalld}^{\mathrm{j} 1}$. On the exercise day, energy intake was also slightly below energy expenditure by $129 \mathrm{~T} 123 \mathrm{kcalId}^{\mathrm{j} 1}$.

Figure 1 contrasts energy expenditure for the exercise and rest days. The exercise bout resulted in a net energy expenditure of $519 \mathrm{~T} 60.9 \mathrm{kcal}$ (contrast in area under the curve, $P$ G 0.001). Hour-by-hour analysis showed that energy expenditure was significantly elevated on the exercise day for $14.2 \mathrm{~h}$ after exercise, corresponding to an increase of $190 \mathrm{~T} 71.4 \mathrm{kcal}$ compared with the rest day. This increase in resting energy expenditure included $3.5 \mathrm{~h}$ of the early sleep period, accounting for $32.0 \mathrm{~T} 39.3 \mathrm{kcal}(P=0.030)$.

Immediately after exercise, subjects sat quietly for $40 \mathrm{~min}$, and the net energy expenditure during this period was $15.4 \mathrm{~T}$ $12.8 \mathrm{kcal}(P=0.001)$. Subjects next were allowed to change clothes and clean themselves with a towel, and the net increase in energy expenditure during this period was $19.3 \mathrm{~T}$ $16.0 \mathrm{kcal}(P=0.004)$. From this point in time to bedtime (a total of $9.7 \mathrm{~h}$ ), the net increase in energy expenditure was $144 \mathrm{~T} 49.9 \mathrm{kcal}$ (P G 0.001). Preexercise periods did not differ between rest and exercise days, and subject movement recorded with the metabolic chamber infrared monitor

TABLE 3. Energy intake and expenditure data (mean T SD).

\begin{tabular}{lccc}
\cline { 2 - 4 } & Rest Day & Exercise Day & $P$ \\
\hline Energy intake data & & & \\
$\quad$ Energy intake (kcalId ${ }^{\mathrm{j}}$ ) & $2400 \mathrm{~T} 448$ & $3058 \mathrm{~T} 462$ & $\mathrm{G} 0.0001$ \\
CHO (\% of energy) & $49.7 \mathrm{~T} 1.4$ & $50.3 \mathrm{~T} 1.1$ & 0.0002 \\
Fat (\% of energy) & $33.3 \mathrm{~T} 1.2$ & $32.8 \mathrm{~T} 0.9$ & 0.0005 \\
$\quad$ Protein (\% of energy) & $16.9 \mathrm{~T} 0.7$ & $16.9 \mathrm{~T} \mathrm{0.6}$ & 0.31 \\
Energy expenditure data & & & \\
$\quad$ Energy expended (kcalId ${ }^{\mathrm{j} 1}$ ) & $2438 \mathrm{~T} \mathrm{475}$ & $3188 \mathrm{~T} \mathrm{559}$ & $\mathrm{G} 0.0001$ \\
RQ & $0.83 \mathrm{~T} \mathrm{0.01}$ & $0.84 \mathrm{~T} \mathrm{0.01}$ & 0.004 \\
\hline
\end{tabular}


was not different between exercise and rest days during this 9.7-h period (data not shown, $P=0.83$ ).

\section{DISCUSSION}

This study found that in healthy young male subjects, vigorous exercise $\left(57 \% \mathrm{~W}_{\max }\right.$ or $\left.73 \% \mathrm{~V} \mathrm{O}_{2 \max }\right)$ for $45 \mathrm{~min}$ starting at 11:00 a.m. resulted in $519 \mathrm{kcal}$ expended above the rest day. Postexercise energy expenditure was significantly elevated for $14.2 \mathrm{~h}$ compared with the rest day, corresponding to an additional $190 \mathrm{~T} 71.4 \mathrm{kcal}$ that included $3.5 \mathrm{~h}$ and $32.0 \mathrm{~T} 39.3 \mathrm{kcal}$ during the early sleep period. Energy intake and expenditure were tightly matched on both the rest and exercise days to ensure zero energy balance under both conditions, and the daily activities of living were controlled.

Most previous studies evaluating the effect of single exercise bouts on postexercise energy expenditure have used Douglas bag and metabolic cart systems, with widely varying results $(6,10,11,13,16,17,22,30)$. This variation is related to multiple factors including noncontinuous measurement of energy expenditure, the use of preexercise RMR as the criteria for normal levels $(6,11,22)$, and the lack of tight control of daily activities of living. Despite these limitations, previous studies emphasize the importance of exercise intensity to produce sizeable increases in postexercise energy expenditure (6). For example, Phelain et al. (23) found that when subjects burned the same amount of calories either through high- or low-intensity exercise, energy expenditure remained elevated at $3 \mathrm{~h}$ after exercise only for the highintensity condition. The magnitude of postexercise energy expenditure is greatest when the body experiences significant physiologic stress during prolonged and high-intensity exercise (4).

Postexercise energy expenditure was significantly elevated for $14.2 \mathrm{~h}$ when compared with the rest day, adding $37 \%$ or $190 \mathrm{~T} 71.4 \mathrm{kcal}$ to the net energy expenditure of the 45-min cycling bout. The duration of increase in postexercise energy expenditure is comparable to Bahr et al. (3), who assessed the effect of high-intensity exercise on excess postexercise oxygen consumption under tightly controlled conditions. In this study, subjects rested or exercised early in the morning and then remained supine in bed for $24 \mathrm{~h}$ while being fed three meals. Using Douglas bag methods, oxygen consumption remained elevated after $12 \mathrm{~h}$ after $40 \mathrm{~min}$ of exercise at $69 \% \mathrm{O}_{2 \max }$. Our magnitude of increase in postexercise energy expenditure (37\%), however, is substantially above the $14 \%$ reported by Bahr et al. (3).

Investigators have used metabolic chambers to measure the influence of exercise on fuel substrates and total 24-h energy expenditure $(18,19,26)$, but only one other chamber study has measured the effect of a single exercise bout on resting energy expenditure (9). Dionne et al. (9) reported no effect of a midafternoon 60-min moderateintensity exercise bout $\left(50 \% \mathrm{~V} \mathrm{O}_{2 \max }\right)$ on 24-h energy expenditure in young adult males compared with a rest day under energy balance conditions. The authors attributed the absence of postexercise changes in energy expenditure to the ingestion of a snack immediately after the 60-min exercise bout (9). This snack contained the same amount of energy and macronutrients oxidized during the exercise bout, and the authors speculated that the snack ingestion caused an accelerated replenishment of glycogen stores and recovery of energy balance. Our results argue against this rationale. The higher exercise intensity in our study caused a greater homeostatic disturbance and more than likely explains the contrast in the magnitude and duration of postexercise energy expenditure.

The prolonged increase in RMR after exercise observed in the current study could have been caused by several contributing factors including an enhanced energy flux. Subjects in our study were maintained in energy balance during both the exercise and rest days, resulting in an added energy intake of $659 \mathrm{kcal}$ on the exercise day. The increased energy intake balanced against energy expenditure (energy flux) has been shown in several studies to contribute to the elevated 24-h energy expenditure on exercise days or in trained individuals $(5,8,12)$. Other potential factors include homeostatic disturbance from vigorous exercise, as theorized by Bahr et al. (4), increased circulation of stress hormones and sympathetic tone (14), and recovery from decreased muscle glycogen levels (14).

Our data support that vigorous cycling (E்70\% V $\mathrm{O}_{2 \max }$ ) has a significant effect on 24-h energy expenditure under conditions when energy intake is balanced with energy expenditure. The magnitude (190 kcal) and duration $(14.2 \mathrm{~h})$ of net energy expenditure after 47 -min cycling at $73 \%$ V $\mathrm{O}_{2 \max }$ are greater than previously reported in most studies conducted outside a metabolic chamber. The 24-h net energy

expenditure difference between exercise and rest days was $750 \mathrm{kcal}$, a meaningful quantity over time if two or three such exercise bouts are inserted into the weekly schedule and energy intake is controlled $(3,4,6)$.

\footnotetext{
This study was supported by internal university funding.

The authors thank Ms. Tondra Blevins for her assistance in operating the metabolic chamber.

No conflicts of interests are reported.

The results of the present study do not constitute endorsement by the American College of Sports Medicine.
}

\section{REFERENCES}

1. American College of Sports Medicine. ACSM's Guidelines for Exercise Testing and Prescription. Baltimore (MD): Lippincott Williams \& Wilkins; 2010. p. 31 - 2.

2. Arciero PJ, Goran MI, Poehlman ET. Resting metabolic rate is lower in women than in men. J Appl Physiol. 1993;75(6):2514 - 20.
3. Bahr R, Ingnes I, Vaage O, Sejersted OM, Newsholme EA. Effect of duration of exercise on excess postexercise $\mathrm{O}_{2}$ consumption. J Appl Physiol. 1987;62(2):485 - 90.

4. Bahr R, Sejersted OM. Effect of intensity of exercise on excess postexercise $\mathrm{O}_{2}$ consumption. Metabolism. 1991;40(8):836 - 41. 
5. Bell C, Day DS, Jones PP, et al. High energy flux mediates the tonically augmented beta-adrenergic support of resting metabolic rate in habitually exercising older adults. J Clin Endocrinol Metab. 2004;89(7):3573 - 8.

6. Brehm BA, Gutin B. Recovery energy expenditure for steady state exercise in runners and nonexercisers. Med Sci Sports Exerc. 1986; 18(2):205 - 10

7. Brychta RJ, Rothney MP, Skarulis MC, Chen KY. Optimizing energy expenditure detection in human metabolic chambers. Conf Proc IEEE Eng Med Biol Soc. 2009;2009:6864 - 8.

8. Bullough RC, Gillette CA, Harris MA, Melby CL. Interaction of acute changes in exercise energy expenditure and energy intake on resting metabolic rate. Am J Clin Nutr. 1995;61(3):473 - 81.

9. Dionne I, Van Vugt S, Tremblay A. Postexercise macronutrient oxidation: a factor dependent on postexercise macronutrient intake. Am J Clin Nutr. 1999;69(5):927 - 30.

10. Elliot DL, Goldberg L, Kuehl KS. Does aerobic conditioning cause a sustained increase in the metabolic rate? Am J Med Sci. 1988; 296(4):249 - 51

11. Freedman-Akabas S, Colt E, Kissileff HR, Pi-Sunyer FX. Lack of sustained increase in $\mathrm{O}_{2}$ following exercise in fit and unfit subjects. Am J Clin Nutr. 1985;41(3):545 - 9.

12. Goran MI, Calles-Escandon J, Poehlman ET, O’ Connell M, Danforth E Jr. Effects of increased energy intake and/or physical activity on energy expenditure in young healthy men. J Appl Physiol. 1994;77(1):366 - 72.

13. Hagberg JM, Mullin JP, Nagle FJ. Effect of work intensity and duration on recovery $\mathrm{O}_{2}$. J Appl Physiol. 1980;48(3):540 - 4.

14. Hunter GR, Byrne NM, Gower BA, Sirikul B, Hills AP. Increased resting energy expenditure after 40 minutes of aerobic but not resistance exercise. Obesity (Silver Spring). 2006;14(11):2018 - 25.

15. LaForgia J, Withers RT, Gore CJ. Effects of exercise intensity and duration on the excess post-exercise oxygen consumption. $J$ Sports Sci. 2006;24(12):1247 - 64.

16. Maehlum S, Grandmontagne M, Newsholme EA, Sejersted OM. Magnitude and duration of excess postexercise oxygen consumption in healthy young subjects. Metabolism. 1986;35(5):425 - 9.

17. Maresh CM, Abraham A, De Souza MJ, et al. Oxygen consumption following exercise of moderate intensity and duration. Eur $J$ Appl Physiol Occup Physiol. 1992;65(5):421 - 6.
18. Melanson EL, Donahoo WT, Grunwald GK, Schwartz R. Changes in 24-h substrate oxidation in older and younger men in response to exercise. J Appl Physiol. 2007;103(5):1576 - 82.

19. Melanson EL, Sharp TA, Seagle HM, et al. Resistance and aerobic exercise have similar effects on 24-h nutrient oxidation. Med Sci Sports Exerc. 2002;34(11):1793 - 800.

20. Nieman DC, Davis JM, Henson DA, et al. Carbohydrate ingestion influences skeletal muscle cytokine mRNA and plasma cytokine levels after a 3-h run. J Appl Physiol. 2003;94(5):1917 - 25.

21. Ohkawara K, Tanaka S, Ishikawa-Takata K, Tabata I. Twentyfour-hour analysis of elevated energy expenditure after physical activity in a metabolic chamber: models of daily total energy expenditure. Am J Clin Nutr. 2008:87(5):1268 - 76.

22. Pacy PJ, Barton N, Webster JD, Garrow JS. The energy cost of aerobic exercise in fed and fasted normal subjects. Am J Clin Nutr. 1985;42(5):764 - 8.

23. Phelain JF, Reinke E, Harris MA, Melby CL. Postexercise energy expenditure and substrate oxidation in young women resulting from exercise bouts of different intensity. J Am Coll Nutr. 1997; 16(2):140 - 6

24. Ravussin E, Harper IT, Rising R, Bogardus C. Energy expenditure by doubly labeled water: validation in lean and obese subjects. $A m$ JPhysiol. 1991;261(3 pt 1):E402 - 9.

25. Sedlock DA, Fissinger JA, Melby CL. Effect of exercise intensity and duration on postexercise energy expenditure. Med Sci Sports Exerc. 1989;21(6):662 - 6.

26. Smith SR, de Jonge L, Zachwieja JJ, et al. Concurrent physical activity increases fat oxidation during the shift to a high-fat diet. Am J Clin Nutr. 2000;72(1):131 - 8.

27. Smith SR, de Jonge L, Zachwieja JJ, et al. Fat and carbohydrate balances during adaptation to a high-fat. Am J Clin Nutr. 2000; 71(2): $450-7$.

28. Storer TW, Davis JA, Caiozzo VJ. Accurate prediction of $V \mathrm{O}_{2 \max }$ in cycle ergometry. Med Sci Sports Exerc. 1990;22(5):704 - 12.

29. Treuth MS, Hunter GR, Williams M. Effects of exercise intensity on 24-h energy expenditure and substrate oxidation. Med Sci Sports Exerc. 1996;28(9):1138 - 43.

30. Turley KR, McBride PJ, Wilmore JH. Resting metabolic rate measured after subjects spent the night at home vs at a clinic. Am J Clin Nutr. 1993;58(2):141 - 4. 